\title{
Quantification of historical history effects in PWR modelling
}

Daniele Tomatis*, Antonio Galia, Stefano Pastoris, Igor Zmijarevic, DEN, Service détude des réacteurs et de mathématiques appliquées, CEA, Université Paris-Saclay, F-91191 Gif-sur-Yvette, France

$13 / 09 / 2016$

\section{Contents}

\begin{tabular}{llr}
\hline & Introduction & 2
\end{tabular}

2 Main features of reactor operation and control in PWR 3

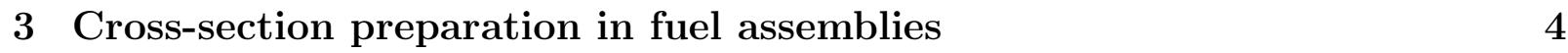

3.1 APOLLO2 calculations . . . . . . . . . . . . . . . . . 4

4 Quantification of historical history effects 5

4.1 Burnup Credit Benchmark . . . . . . . . . . . . . . . . . . 6

4.2 Varying boron dilution . . . . . . . . . . . . . . . . . . . . . . . . . . . . . . . . . . . . . . . . . . . . . . .

4.3 Different moderation in the coolant . . . . . . . . . . . . . . . . . . . . 10

4.4 Permanent control rod insertion . . . . . . . . . . . . . . . . . . . . . . . . . . . . . . . . . . . . .

4.5 Control rod aging . . . . . . . . . . . . . . . . . . . . . . . . . . . . . . . . . . . . . .

4.6 Local pin reaction rates . . . . . . . . . . . . . . . . . . . 20

$\begin{array}{llr}5 & \text { Conclusion } & 20\end{array}$

\begin{abstract}
Nowadays, the application of nodal methods and cross section homogenization is a standard practice in reactor core design and safety studies. Specifically, nodal cross sections are prepared with the planned physical operating conditions in the single fuel assemblies, thus assuming different approximations like for instance a constant
\end{abstract}

*Corresponding author: daniele.tomatis@cea.fr 
exposure at nominal power. Concerning the light water reactors, this scheme was especially suitable for the first PWR units operating on base load, and much less for BWRs due to the strong core heterogeneities and strong axial water density variation which required ad-hoc corrections. The new generation of PWRs and yet the current units in Europe show frequent use of control rod elements in order to operate on load-following. In general, the current few group cross section models of core simulators are not designed to cover very long periods of control bank insertions, thus arising the problem of the physical representation. In this work, we quantify the errors on nodal cross sections in presence of strong insertion of control rods, using the classical approach for the cross sections preparation based on a single PWR assembly homogenization. The framework of the Burn-up Credit Criticality Benchmark NEA-6227 (Phase II-D) is used to model different rodded configurations of a UO2 fuel assembly by the lattice code APOLLO2.8, providing also additional validation elements for the code. Different insertion patterns along the multiple core cycles are investigated and differences against the standard cross section generation, which considers the control rods insertion only as a perturbation along the exposure in the nominal depletion sequence, are studied. Still using the framework of this benchmark, other test cases are formulated to investigate the influence of varying boron concentration along the fuel cycles, different power levels and water densities and the aging of control elements. In particular, the latter is marked as potential issue when staging a very long insertion as with the main cases of the benchmark. We also discuss mesh refinement to model "the skin effect" when depleting the absorption materials of control rods. The suggestions for the improved modelling are given in the conclusion.

Keywords - Cross section preparation, PWR, control rods, history effects.

\section{Introduction}

The use of nodal methods or finite element methods have allowed in years the development of very efficient computer codes to carry numerical simulations of nuclear reactors [1]. Certainly, this would have never been possible without the important advances in homogenization theory, which started from the late 70s and provide standard methodologies for nowadays calculations [2, 3, 4].

Provided a coupling scheme with thermal-hydraulic codes, nodal cross sections and equivalence factors are then prepared using the multigroup formalism in several different configurations in order to represent the operation of the nuclear reactor [5]. A limited set of reactor-dependent state parameters is needed in order to reproduce accurately the system reactivity and the power distribution. Common choices of state parameters account for instantaneous nuclide densities and thermo-physical properties, which are input data for the whole cross section preparation. The different reactor states are determined as perturbed conditions with respect to a reference configuration, which follows base irradiation histories. This implies also a few main depletion histories, fixing the isotopic content for all calculations in the perturbed conditions.

Such schemes have been widely used in reactor modelling with satisfactory results. Indeed, local heterogeneities like for instance control rod mechanisms, occurring at operation and control of the reactor, are covered by this model only for short insertion in time, not altering considerably the flux spectral history presumed at cross section preparation. Although the presence of permanent controlled fuel assemblies has always been quite common in the bottom region of BWRs, control rods were generally used only for short periods in PWRs during power operation to allow for first base load regulation. The need of load 
following forced more controlled core patterns in PWRs too, especially in France where the electrical power production is largely coming from nuclear power plants. In addition, an increasing trend in the design of light water reactors towards highly controlled fuel assemblies is remarked mostly to guarantee enhanced load follow capabilities and reduced operation costs for boron chemical shim [6, 7]. Eventually, long insertion of temporary strongly absorbing materials remains a cumbersome topic for nodal core codes, needing often additional models to apply conservative corrections in design and safety studies.

Different solutions are proposed in the literature to take into account long insertion of control elements in nodal codes. The most of them apply corrections based on a new quantity derived from the spectral index, called spectral history, where the spectral index is the ratio between fast and thermal scalar fluxes of the two group scheme of thermal reactors. Different definitions are also noticed for the spectral history, though the most common integrates the spectral index along the burnup and makes the ratio with the total burnup cumulated $\left[8,9,10,11\right.$. Others recur to the actual ${ }^{239} \mathrm{Pu}$ concentration to recover the spectral history effects [12. In general, cross section sections are prepared with different depletion histories, in addition to the main irradiation at nominal power. The burnup or exposure dependence of the few group cross sections comes from the nominal depletion calculation, while the different depletion histories are based on combination of nominal points and parameters, such as the spectral history, describing the actual conditions. For instance, BWRs show also historical historic void fraction or moderator density [9, 13, 14]. According to Mosteller, the moderator history was also considered in PWR simulation to get more accurate cross sections at the top and bottom parts of the reactor [15].

It is therefore necessary to investigate in detail the history effects on cross section homogenization due to strongly controlled configurations. First, the test cases of the burnup criticality credit benchmark (phase II-D) [16] are used to model a uranium assembly with different insertion patterns along multiple core cycles. Calculations are performed with APOLLO v.2.8, 17] providing additional validation in favor of the codes and the lattice calculation scheme, detailed in Section 3.1. Differences against the standard cross sections preparation showing control rods inserted only punctually along the exposure are studied. Still using the framework of this benchmark, other test cases are formulated to investigate the influence of varying boron concentration along the fuel cycles, different wer le water densities and aging of control elements. In particular, the latter is marked as potential issue when staging very long insertion as with the main cases of the benchmark [18]. We also discuss mesh refinement to consider the so-called skin effect when depleting the absorption materials of control rods [19. This work is not meant formulating new parameters to model few group cross sections, although suggestions will be mentioned in the conclusion.

\section{Main features of reactor operation and control in PWR}

Power levels and criticality are maintained by control rod elements and boron shim in PWRs. The former mean spots near-term regulation, whereas the latter schedules long-term control all along the core cycle. This difference is due to technical latency at operation, because of the limited mass flow of treated coolant water at borication and dilution, and prompt electro-magnetic drive mechanisms of control rods.

Regardless of previous core exposure, control rods are progressively extracted from hot zero power (HZP) conditions to reach hot full power (HFP) conditions, and then starting operation on base load. Insertion at power is temporary, or occasional in case of power load-following mode. On the other hand, boron shim is strictly related to the core cycle history, with higher content of boron diluted in water at beginning of cycle (BOC) until achieving a few ppm at the end of cycle (EOC).

Traditional cross section preparation for computer core simulators complies with these specific operating aspects. Neutron transport calculations on 2D lattices model the behavior of the single fuel assembly along different batches in the core under exposure. Fuel inventory is updated at different burnup steps using detailed depletion chains and critical neutron spectra. The occurrence of control rods or instrumentation is not considered when depleting, but introduced on demand at given burnup values to later feed a 
few group cross section model for the core calculations. Also, these assembly calculations often disregard any varying boron concentration in favor of an average value.

New reactor designs show however stronger utilization of control rod elements, mainly to restrict boron shim with lower amounts of effluents and water treated at the chemical volume and control system (CVCS). This is the case with the new EPR reactor from AREVA [7] and the AP1000 from Westinghouse 6, 10, 6].

The presence of control elements in the assemblies hardens the neutron spectrum because of decreased efficiency in the neutron slowing down process and of higher absorption in the thermal range. Under these conditions, the plutonium build-up is favored and the consumption of fissile uranium isotopes lessen slightly. Protracted insertion may provide moderate savings of ${ }^{235} \mathrm{U}$ and discrete amount of fissile plutonium isotopes. This phenomenon is directly related to the neutron absorption efficiency of the control bank, being much more significant with black rods for further depression of the thermal flux.

These-Since the weighting neutron spectra depend on the exposure history these effects are not covered in general by the few group cross section models largely used for reactor analysis, possibly succeeding in new safety issues. New safety issues may arise especially when prolonged insertion of control elements is operated. Specifically, an unexpected positive reactivity excess could be noticed after the extraction of a bank longly inserted because of unphysical cross sections prepared with a totally different history. After recalling the standard procedure of cross section preparation, several cases are treated in the following sections to investigate these historical history effects.

\section{Cross-section preparation in fuel assemblies}

According to the standard practice, core calculations are performed on coarse meshes and with few group cross sections. These last, which must be prepared a priori in new data-libraries to cover later the physical conditions of the core calculations. The preparation treats separately the different kinds of fuel assemblies loaded in the reactor. By means of the homogenization paradigm, lattice transport problems are solved on the bi-dimensional geometry of the fuel assembly using reflection or periodic boundary conditions, to then homogenize in space per quadrant and condense in energy in the only fast and thermal ranges. Self-shielding is here necessary due to the resonant behavior of the constituting isotopes and to the many resonances of nuclear events. Few group homogenized cross sections follow as conservation of the corresponding reaction rates as:

$$
\Sigma_{x, G}=\frac{\int_{\Theta} \Sigma_{x} \Phi d \theta}{\int_{\Theta} \Phi d \theta},
$$

where $x$ refers to the reaction and integration is over the assembly volume and in the energy group $G$ represented by $\theta$. The input quantities characterizing these averages are the isotopic content and the local thermo-physical properties, provided that the geometry of the assembly does not change. Here is the importance of the exposure history in order to prepare accurate cross sections.

A few group data library normally comes with additional equivalence factors needed to ensure physical equivalence between the cross section preparation environment and the real one in the core. In this work, equivalence is not considered since it would require additional considerations about the specific eodecore code used, more precisely , about the numerical discretization scheme used for core calculations. We recall that this analysis is conducted on the basis of produced homogenized cross sections produced by lattice calculations, without applying them to the actual core calculation. The cross sections thus depend only on the conditions of the lattice ealculation calculations without the alteration that would be introduced in order to adapt them to a given flux solver.

\subsection{APOLLO2 calculations}

In this study, -the APOLLO2 code [17] revisits the Burn-up Credit Criticality Benchmark [16], which at that time was calculated using the cross section library based on JEF-2JEFF-2.2. Two different method 
methods of resolution were then employed: a straightforward, standalone APOLLO2.5 version with 172group library and direct collision probability method, and 20-group discrete ordinates calculations on homogenized cells, where APOLLO2 has been used as a part of CRISTAL package 20. Since then, the code acquired many additional and important features including the method of characteristics (MOC) that became the main flux solver option.

The flux calculations presented here were performed using 281-group cross section library based on JEFF-3.1, with the step option of the MOC flux solver and the $P_{3}$ anisotropic scattering. The trajectories along which the MOC solves the balance and transmission equations were defined using the following parameters: parallel trajectories spacing was equal to $0.05 \mathrm{~cm}$, with the angular quadrature of product type, where the azimuthal spacing was $\pi / 24$, with three polar angles following the Legendre quadrature between 0 and $\pi / 2$.

The depletion calculation is performed using the predictor-corrector scheme based on parabolic extrapolation/interpolation, while solving the Bateman equations with the fourth order Runge-Kutta method. At each depletion step the flux is recalculated with the new self-shielded cross-sections and the convergence is guaranteed by imposing a criterion of $\epsilon_{r}=0.025 \epsilon_{r}=0.025$ as relative difference of isotopic concentrations and the values of depletion matrix between the predictor and corrector steps. The procedure is set in a way that, in the case of insufficient convergence, and within a given tolerance $\left(\epsilon_{r} ; 0.2 \epsilon_{x} \leqslant 0.2\right)$, the depletion step is reduced automatically and the calculation is repeated. This situations situation has been monitored in order to insure an accurate depletion step lengths.

The standard self-shielding options of APOLLO2, based on Livolant-Jeanpierre formalism is used 21, 22, Self-shielding is done for all actinide isotopes, principal fission products and the constituents of the cladding, burnable absorber pins and control rods. These are: ${ }^{107} \mathrm{Ag},{ }^{109} \mathrm{Ag},{ }^{109} \mathrm{Ag},{ }^{110} \mathrm{Cd},{ }^{113} \mathrm{Cd},{ }^{241} \mathrm{Am},{ }^{243} \mathrm{Am}$, $\mathrm{Gr}^{\text {nat } \mathrm{Cr},{ }^{133} \mathrm{Cs},{ }^{153} \mathrm{Eu}, \mathrm{Fe}}{ }^{\text {nat }} \mathrm{Fe},{ }^{154} \mathrm{Gd},{ }^{155} \mathrm{Gd},{ }^{156} \mathrm{Gd},{ }^{157} \mathrm{Gd},{ }^{158} \mathrm{Gd},{ }^{160} \mathrm{Gd},{ }^{115} \mathrm{In},{ }^{95} \mathrm{Mo},{ }^{143} \mathrm{Nd},{ }^{145} \mathrm{Nd}$, isot Ninat $\mathrm{Ni},{ }^{237} \mathrm{~Np},{ }^{238} \mathrm{Pu},{ }^{239} \mathrm{Pu},{ }^{240} \mathrm{Pu},{ }^{241} \mathrm{Pu},{ }^{242} \mathrm{Pu},{ }^{103} \mathrm{Rh},{ }^{101} \mathrm{Ru},{ }^{147} \mathrm{Sm},{ }^{149} \mathrm{Sm},{ }^{150} \mathrm{Sm},{ }^{151} \mathrm{Sm},{ }^{152} \mathrm{Sm}$,

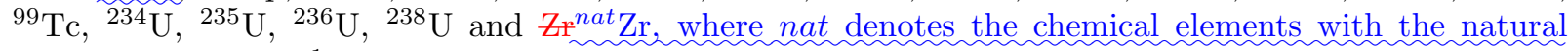
isotopic abundances ${ }^{1}$. The options for the treatment of the resonance interferences (resonant mixtures model) are chosen for ${ }^{235} \mathrm{U},{ }^{238} \mathrm{U},{ }^{239} \mathrm{Pu}$ and ${ }^{240} \mathrm{Pu}$.

MoreoverUnlike the cases of the burnup criticality benchmark treated in sec. 4.1, the $B_{1}$ fundamental mode leakage model was imposed to obtain a critical flux in the cases where the leakage is accounted for 22 .

The typical discretization that accurately reproduces the spatial variation of the effective cross sections due to self-shielding effect and the isotopic concentrations during the cycle, comprises the four annular regions in an ordinary fuel pin that contain different macroscopic cross sections. In the case of gadolinium bearing pins the pin volume is divided into eleven equivolumic rings. A typical spatial mesh of the MOC flux calculator is presented in Fig. 1. Every ring in every pin depletes independently, while the sets of four (or eleven) self-shielded cross sections are shared between the pins that are gathered into groups according to pin position and environment. That means that the pins having one or more different neighbors that face it laterally and or at the corner, belong to different groups of averaged self-shielding pins. The number of different groups (selfshielding self-shielding fuel pins) vary then between 5 for the simple UOX assembly without control rods nor gadolinium pins, to 13 for gadolinium assembly.

\section{Quantification of historical history effects}

In this section the effects of long CR insertionand_ varying boron along the whole in-core fuel cycle and different moderating conditions in the coolant are investigated. They are here studied within the framework of the following "burnup credit benchmark".

Differences, always related to the quantities calculated with the nominal depletion (without rod inserted), are provided for isotopic concentrations, microscopic cross sections and for some integral quantities

\footnotetext{
${ }^{1}$ For isotopic compositions of natural elements see 23 .
} 


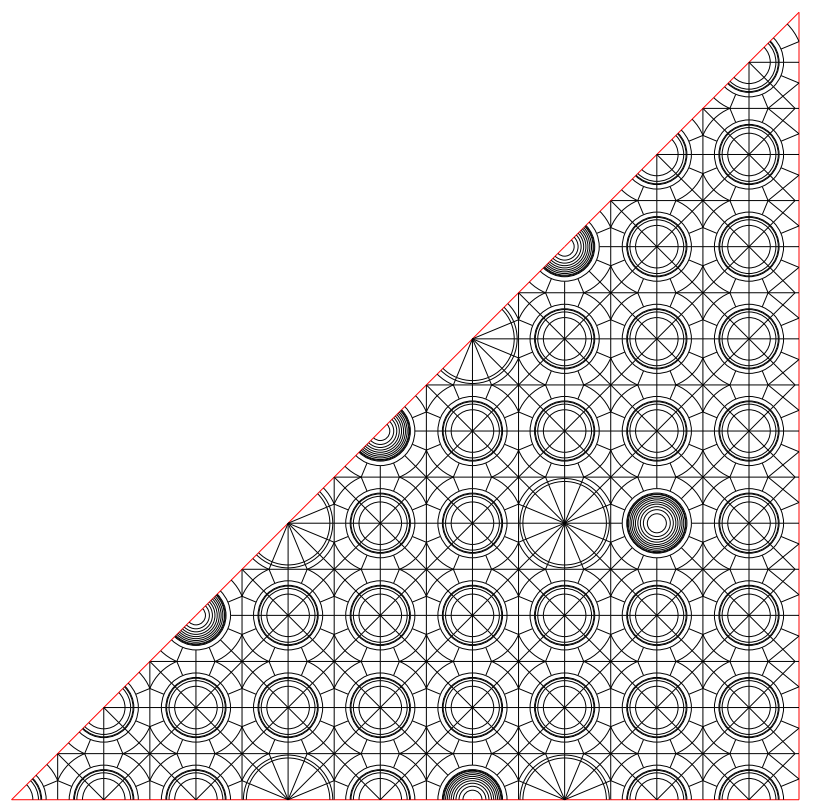

Figure 1: Spatial mesh of the MOC solver on a gadolinium assembly. One eighth of a $17 \times 17$ cell symmetric assembly is calculated.

of interest, such as the reactivity $\rho=1-1 / k_{\infty}$, the spectral index $S I=\Phi_{1} / \Phi_{2}$ and the spectral history $S H$ :

$$
S H=\frac{1}{B u} \int_{0}^{B u} \frac{S I}{S I_{N}} d B u^{\prime},
$$

where $\Phi_{1}$ and $\Phi_{2}$ are respectively the fast and the thermal neutron fluxes ${ }^{2}$, and the subscript $N$ refers to the conditions at nominal depletion. Reactivity is here determined by the multiplication factor in the infinite medium, $k_{\infty}$. In case a leakage model is used for the depleting flux, $k_{\infty}$ is calculated as ratio of production to absorption rate computed with the critical spectrum.

\subsection{Burnup Credit Benchmark}

The benchmark NEA-6227 (Phase II-D) studies the impact of control rod insertion on spent fuel composition and on reactivity of a PWR UO2 assembly [16. A set of test cases with different CR insertion profiles during irradiation is proposed, and it is requested to calculate the spent fuel inventory, the neutron multiplication factor and its sensitivity to the most important isotopes in cold pool conditions after the plant shutdown.

The fuel assembly has $17 \times 17$ rods with 25 guide tubes, see Fig. 2 it is modeled with reflective boundary conditions. The calculation of the reactivity by the infinite multiplication factor along the exposure steps does not take into account the leakage correction. All material and geometrical specifications are not repeated here, they are fully detailed in the benchmark report [16].

The fuel assembly is exposed up to two levels of burn-up, $30 \mathrm{GWd} / \mathrm{t}$ and $45 \mathrm{GWd} / \mathrm{t}$, and depleted with the cooling times of zero and five years. The given exposures represent possible utilization options in a three batch per cycle loading scheme. In this work, we present the results of the test cases listed in table 1. Specifically, fuel inventory and criticality are determined for Cases 1 to 8 , whereas material

\footnotetext{
${ }^{2}$ Energy cut-off at $0.625 \mathrm{eV}$.
} 


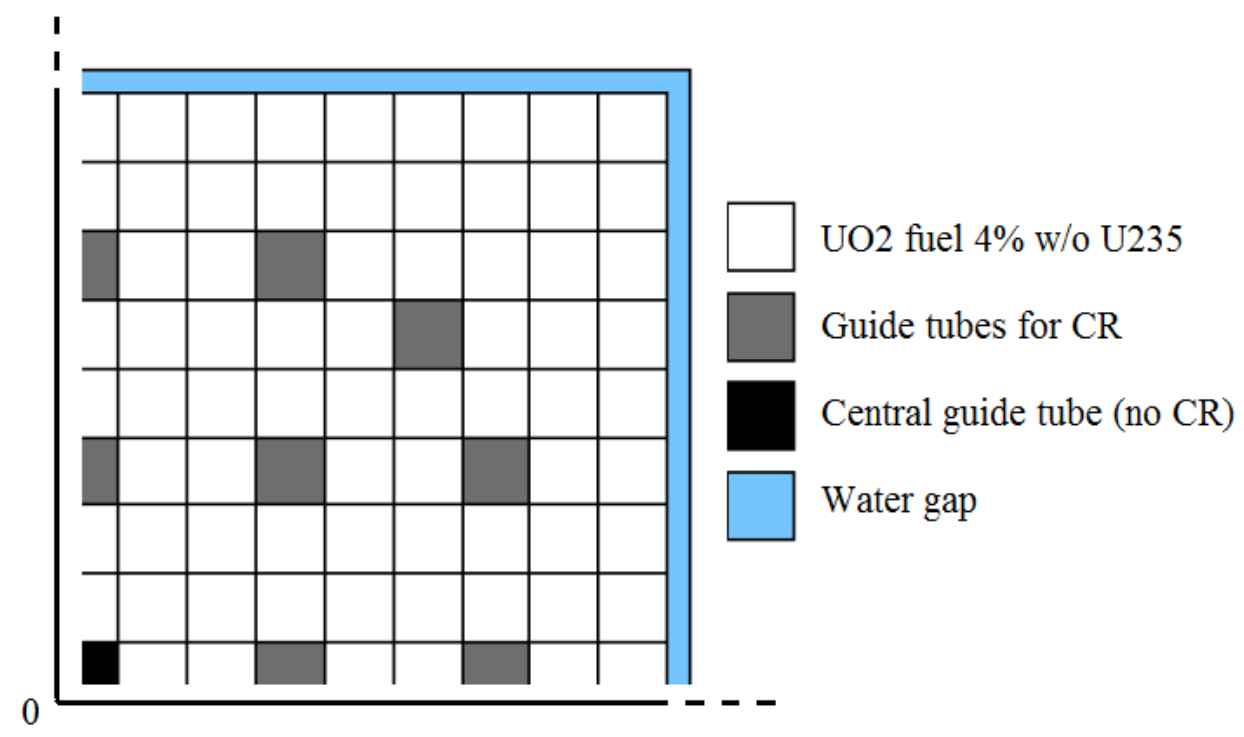

Figure 2: North-East UO2 FA quadrant.

compositions are given in the other cases to validate the calculation scheme and the used data libraries (JEFF-3.1 based). Case 15 requests criticality of the fresh fuel.

Table 1: List of benchmark test cases considered in this study.

\begin{tabular}{|c|c|c|c|}
\hline $\begin{array}{c}\text { ease-Case } \\
\text { nb. }\end{array}$ & $\begin{array}{l}\text { Cooling } \\
\text { time }(y)\end{array}$ & $\begin{array}{c}\mathrm{CR} \text { insertion } \\
\text { period }(\mathrm{GWd} / \mathrm{t})\end{array}$ & $\begin{array}{c}\text { Fuel inventory } \\
\text { burnup }(\mathrm{GWd} / \mathrm{t})\end{array}$ \\
\hline 1 & \multirow{8}{*}{0} & OUT & 30 \\
\hline 2 & & $0-30$ & 30 \\
\hline 3 & & OUT & 45 \\
\hline 4 & & $0-45$ & 45 \\
\hline 5 & & $0-15$ & 45 \\
\hline 6 & & $15-30$ & 45 \\
\hline 7 & & $30-45$ & 45 \\
\hline 8 & & $0-30$ & 45 \\
\hline $13 b$ & \multirow{2}{*}{5} & OUT & 45 \\
\hline $14 b$ & & $0-45$ & 45 \\
\hline 15 & - & $0-45$ & 0 \\
\hline
\end{tabular}

Tab. 2 shows the results of the requested criticality calculations in terms of multiplication factor $k_{\infty}$ (simply $k$ in the table) ${ }^{3}$ and the errors differences relative to the reference value, $k^{*}$, which is set as the average benchmark result taking into account the results of all participants. The table shows also the root mean square $(R M S)$ of absolute errors of all participants relative to $k^{*}$. In general, APOLLO2.8 computes multiplications-multiplication factors very close to the average values from the benchmark, largely within

\footnotetext{
${ }^{3} k_{\infty}$ refers to the specific reflection boundary conditions applied, here equal to the eigenvalue $k_{\text {eff }}$ for the absence of a leakage model.
} 
one standard deviation. The calculation scheme with the selfshielding self-shielding options and the nuclear data library used are validated by Cases $13 \mathrm{~b}, 14 \mathrm{~b}$ and 15 that show imposed material compositions. The fuel inventory results along exposure (Cases from 1 to 8 ), in terms of relative differences of isotopic concentrations (\%) are collected in Tab. 3. $R M S$ of relative errors is also shown aside (right column in each case). Once again the reference value is taken to be the average concentration provided by all participants of the benchmark-.

The sensitivities of the multiplication factor to a variation of $1 \%$ of the isotopic concentration are available in Tab. 4. The highest values are found for the isotopes ${ }^{235} \mathrm{U},{ }^{238} \mathrm{U}$ and ${ }^{239} \mathrm{Pu}$, around $100 \mathrm{pcm} / \%$. Then ${ }^{240} \mathrm{Pu},{ }^{241} \mathrm{Pu},{ }^{143} \mathrm{Nd}$ and ${ }^{149} \mathrm{Sm}$ follow in order, with values between 10 and $65 \mathrm{pcm} / \%$. Comparing the results with the values of the benchmark report, it is noticed that the coefficients estimated by APOLLO2.8 are in general slightly higher, with a maximum difference in Case 1 for ${ }^{235} \mathrm{U}$, yielding $20 \mathrm{pcm} / \%$ higher. This case is among those with larger error on the $k_{\infty} k_{\infty}$.

Table 2: Multiplication factors $\left(k_{\infty}\right)$ of the test cases in Tab. 1. $k^{*}$ that refers to the average values, as well as $R M S$ are taken from the benchmark report. Differences in $k$ $\left(\Delta k=k^{*}-k_{A P 2.8}\right)$ and $R M S$ values are in $\mathrm{pcm}\left(\times 10^{5}\right)$.

\begin{tabular}{c|c|c|r|r} 
Case & $k_{A P 2.8}$ & $k^{*}$ & \multicolumn{1}{|c|}{$\Delta k$} & $R M S$ \\
\hline 1 & 1.09734 & 1.09952 & -218 & 681 \\
2 & 1.14709 & 1.14748 & -39 & 547 \\
3 & 0.99167 & 0.98994 & +173 & 1025 \\
4 & 1.08078 & 1.07841 & +238 & 839 \\
5 & 1.01221 & 1.01281 & -60 & 940 \\
6 & 1.01960 & 1.01956 & +5 & 972 \\
7 & 1.04416 & 1.04439 & -23 & 908 \\
8 & 1.03930 & 1.03895 & +35 & 908 \\
$13 \mathrm{~b}$ & 0.93904 & 0.93921 & -17 & 223 \\
$14 \mathrm{~b}$ & 1.02650 & 1.02639 & +11 & 235 \\
15 & 1.33981 & 1.34102 & -121 & 169
\end{tabular}




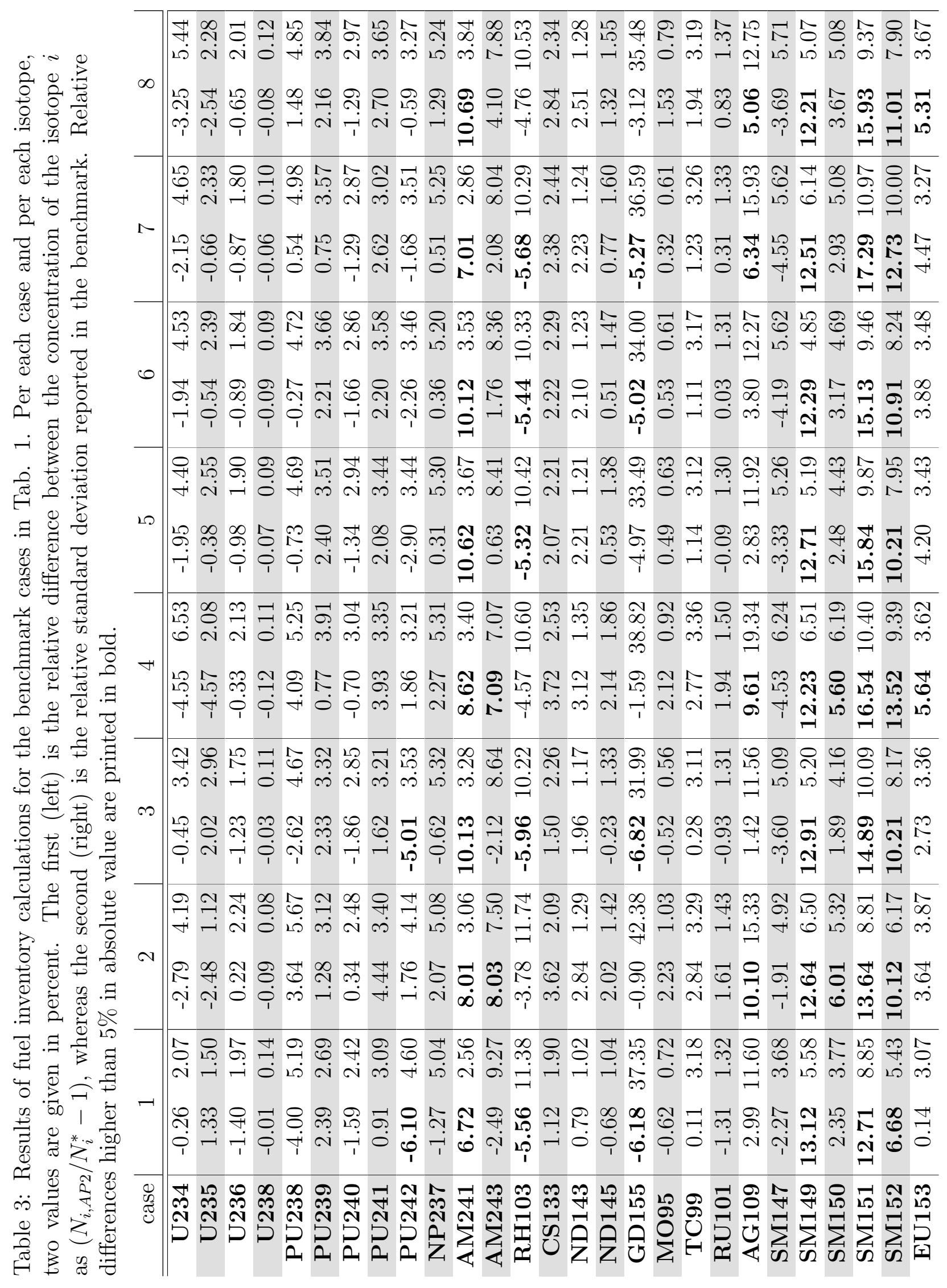


The benchmark tests show general good agreement of the APOLLO2.8 results, except for the evolution of a few isotopes, such as samarium, americium and neodymium - (as shown in Tab. 3 . It is noticed however that the standard deviation among the participants is sometimes quite high (gadolinium in primis). This is certainly due to the different methods, libraries and calculation schemes used by the participants. Clear differences are also observed in the concentrations of many fission products, and they increase with fuel exposure. Here agin, data-Data libraries are retained here as the main cause of error.

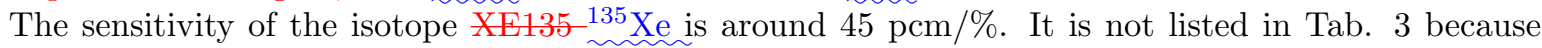
of unavailable benchmark data. Although saturation of the poison is expected at a given power, its concentration is changing along the burnup due to spectrum hardening.

For the depletion calculation, no leakage model is specified by the benchmark; so it was not implemented in this calculation scheme. Moreover, the presence of results from Monte Carlo codes suggests to simply disregard it.

Control rod insertion has here a severe impact on the reactivity with thousands of pcm, particularly over periods of two/three cycles $(30-45 \mathrm{GWd} / \mathrm{t})$. However, these remain extreme cases serving the purpose of understanding the neutron physics in the fuel assembly.

\subsection{Varying boron dilution}

The quantity of boron diluted in the moderator drops to a few tens of ppm towards the end of cycle (EOC) for the long-term criticality control. Temporary variations may follow also with thermal power changes, compensating the coming antireactivity of the Xenon poisoning. Typically, constant boron content is used to produce homogenized data libraries ( $456 \mathrm{ppm}$ in the benchmark above). In this section a varying boron profile is proposed instead, with the $B_{1}$ leakage model too. The profile is simply linearly decreasing in the burnup $-B u$, as $2 * 456 *(1-B u / 15)(\mathrm{GWd} / \mathrm{t})$ as $2 \times 456 \times(1-B u / 15) \mathrm{ppm}$ in the first cycle, and repeated in later cycles in order to yield the benchmark value as average in each cycle. In Fig. 3 , it is interesting to notice that the reactivity computed without the history of the linear boron profile, but using the boron concentrations of the profile (dotted line, in further text reffered referred as of boron punctual), does not make significant difference. differences. A varying boron profile causes a higher reactivity penalty at BOC, but milder fuel consumption to achieve higher reactivity at EOC. Also the plots of the SI and of the SH confirm negligible historieal-history effects on the reactivity. The absolute errors in $t_{\infty} k_{\infty}$ at 15,30 and $45 \mathrm{GWd} / \mathrm{t}$ are respectively about $20 \mathrm{pcm}, 170 \mathrm{pcm}$ and $450 \mathrm{pcm}$, with maximum 1-2\% off in the concentrations of ${ }^{235} \mathrm{U}$ and ${ }^{239} \mathrm{Pu}$. A constant boron concentration at the cycle-equivalent value seems then appropriate when using a leakage model.

\subsection{Different moderation in the coolant}

The enthalpy increase of the coolant along the lattice channels implies different moderating conditions for neutrons. Although higher temperature promotes the scattering with hydrogen bound in water, the reduction of the moderator density decreases the slowing-down rate. Hence, spectrum hardening is expected towards the core outlet, and a better thermalization at inlet.

In this section the history of the fuel assembly at the core inlet and outlet conditions is compared with the nominal exposure. Typical conditions of a 900MWe French PWR unit are assumed: inlet and outlet temperatures of $287^{\circ} \mathrm{C}$ and $324^{\circ} \mathrm{C}$ respectively, and nominal temperature of $300^{\circ} \mathrm{C}$, primary pressure of 155 bar 24 .

Fig. 4 shows the trend of the reactivity and of the spectrum along exposure for the cases at which the fuel depletes at the three different conditions (NOMINAL, at core INLET and OUTLET). As well, the cases corresponding to instantaneous variation of the thermodynamic properties of the coolant, still keeping nominal conditions while depleting at HFP, are also reported (INLET-punct and OUTLET-punct). Since the history effects are not taken into account in the branch calculations, errors of the order of $5 \%$ on the SI and greater than $1 \%$ on reactivity are noticed at the end of the third fuel cycle with outlet 
Table 4: Sensitivity of neutron multiplication factor to concentration changes. $\Delta k / \Delta N_{i}$ due to a variation of $1 \%$ of the isotope concentrations. Units are in pcm/(1\%). APOLLO2 results are in the first column for each case, and the benchmark participants average is in the second. Coefficients higher than $10 \mathrm{pcm} /(1 \%)$ are printed in bold.

\begin{tabular}{|c|c|c|c|c|c|c|c|c|}
\hline case & \multicolumn{2}{|c|}{1} & \multicolumn{2}{|c|}{2} & \multicolumn{2}{|c|}{3} & \multicolumn{2}{|c|}{4} \\
\hline$\overline{\overline{\text { U234 }}}$ & $\overline{-1.3}$ & \begin{tabular}{c|}
-1.3 \\
\end{tabular} & 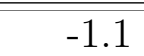 & $\overline{-1.1}$ & 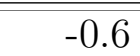 & 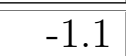 & 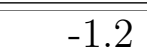 & $\overline{-2-0.8}$ \\
\hline U235 & 168.3 & 149.9 & 140.5 & 120.6 & 124.0 & 121.7 & 101.7 & 94.8 \\
\hline U236 & -4.3 & -3.9 & -3.9 & -3.7 & -4.0 & -4.1 & -4.4 & -4.1 \\
\hline U238 & -134.2 & -121.6 & -124.5 & -108.5 & -124.0 & -123.4 & -114.4 & -106.4 \\
\hline PU238 & -1.6 & -1.5 & -1.5 & -1.7 & -3.8 & -4.2 & -4.2 & -4.2 \\
\hline PU239 & 107.8 & 97.3 & 110.6 & 96.8 & 153.6 & 153.8 & 144.2 & 134.9 \\
\hline PU240 & -38.9 & -35.7 & -39.3 & -35.1 & -47.7 & -48.9 & -48.6 & -45.1 \\
\hline PU241 & 34.3 & 31.2 & 33.9 & 29.8 & 63.8 & 64.1 & 57.3 & 54.1 \\
\hline PU242 & -1.6 & -1.5 & -1.6 & -1.5 & -3.1 & -3.2 & -3.3 & -3.0 \\
\hline NP237 & -3.7 & -3.5 & -3.9 & -3.9 & -5.8 & -6.1 & -6.3 & -6.3 \\
\hline AM241 & -1.0 & -0.8 & -0.9 & -1.0 & -1.3 & -1.6 & -2.1 & -1.9 \\
\hline AM243 & -0.5 & -0.4 & -0.4 & -0.5 & -1.4 & -1.6 & -1.5 & -1.6 \\
\hline RH103 & -8.9 & -8.0 & -8.3 & -7.4 & -11.3 & -11.5 & -11.2 & -10.0 \\
\hline CS133 & -4.4 & -4.2 & -3.9 & -3.8 & -5.7 & -5.9 & -5.7 & -5.2 \\
\hline ND143 & -16.3 & -14.4 & -14.1 & -12.2 & -20.1 & -20.0 & -18.5 & -16.5 \\
\hline ND145 & -2.4 & -2.5 & -2.3 & -2.3 & -3.3 & -3.7 & -3.5 & -2.9 \\
\hline GD155 & 0.3 & -0.1 & 0.1 & -0.2 & 0.2 & -0.2 & -0.5 & -0.4 \\
\hline MO95 & -1.5 & -1.3 & -1.2 & -1.2 & -1.7 & -2.2 & -1.8 & -1.7 \\
\hline TC99 & -3.1 & -2.8 & -2.8 & -2.5 & -3.8 & -4.0 & -3.9 & -3.5 \\
\hline RU101 & -1.2 & -1.0 & -0.6 & -0.8 & -1.2 & -1.4 & -1.8 & -1.3 \\
\hline AG109 & -1.0 & -1.0 & -0.9 & -1.0 & -1.6 & -1.8 & -2.1 & -1.6 \\
\hline SM147 & 0.0 & -0.5 & -0.3 & -0.5 & -0.5 & -0.8 & -1.0 & -0.7 \\
\hline SM149 & -11.1 & -11.3 & -14.3 & -14.5 & -9.9 & -11.4 & -14.1 & -14.9 \\
\hline SM150 & -1.6 & -1.6 & -1.4 & -1.4 & -2.3 & -2.7 & -2.2 & -2.1 \\
\hline SM151 & -8.4 & -9.0 & -10.0 & -10.3 & -9.9 & -11.6 & -11.8 & -13.2 \\
\hline SM152 & -2.9 & -2.9 & -2.2 & -2.4 & -3.4 & -4.0 & -3.4 & -3.3 \\
\hline EU153 & -2.5 & -2.4 & -2.3 & -2.2 & -3.9 & -4.2 & -4.2 & -3.7 \\
\hline
\end{tabular}




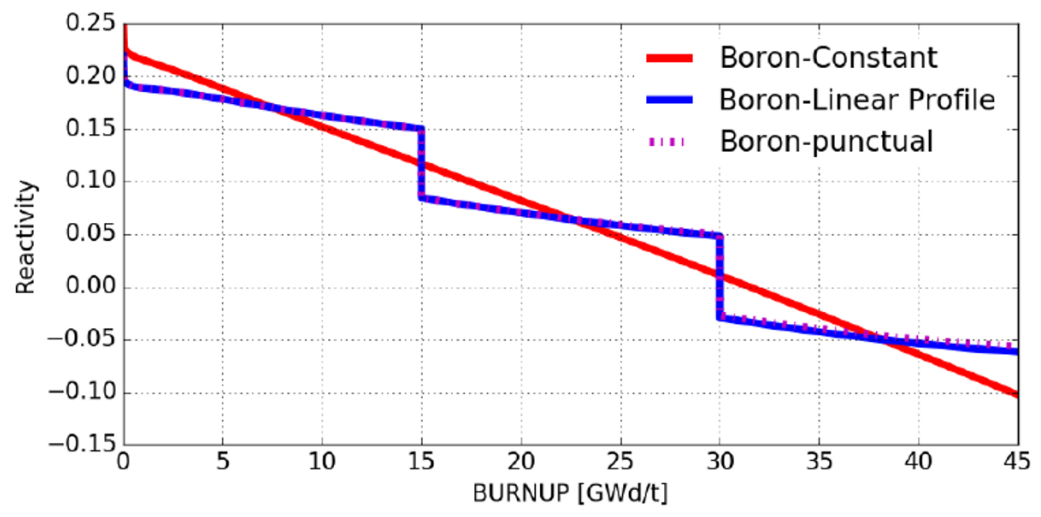

(a) Reactivity evolution.
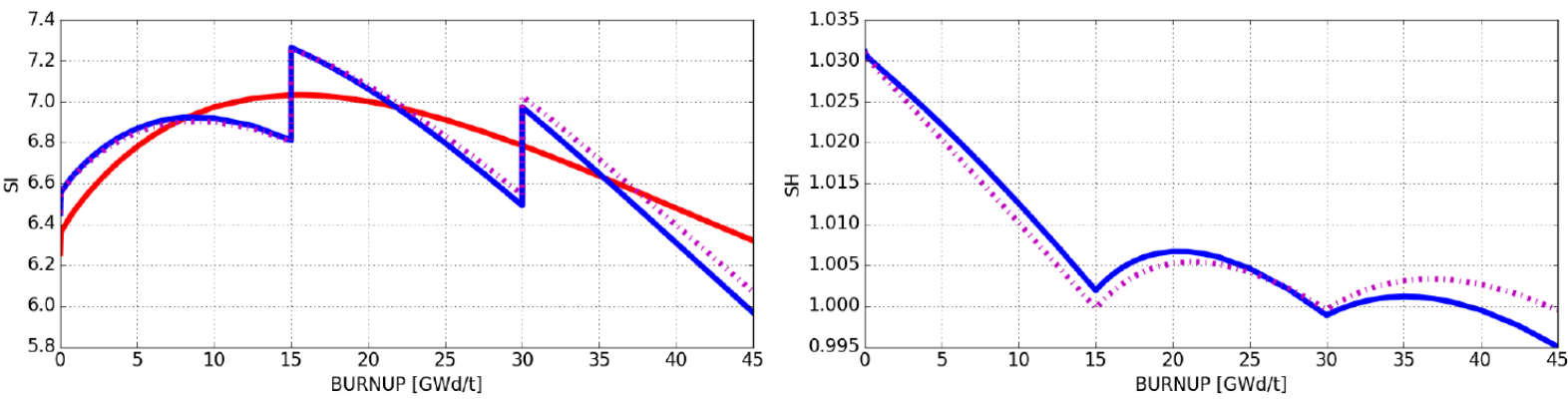

(b) SI and SH.

Figure 3: Results with constant and varying boron along exposure. 
moderator conditions. Differences of reactivity are quite limited during the first cycle instead. Smaller errors occur with inlet conditions, since these are closer to the nominal ones.

Fig. 5a provides the impact on the isotopic concentrations at the end of the third cycle, caused by the variation of the moderator density. Negative errors mean lower concentrations with respect to the nominal depletion and vice-versa, thus showing better usage of ${ }^{235} \mathrm{U}$ and lower production rate of ${ }^{239} \mathrm{Pu}$ at the inlet due to a better thermalization, and an accumulation of fissile material at the outlet because of spectrum hardening. Fig. $5 \mathrm{~b}$ shows the homogenized microscopic cross section of thermal fissions for the isotope ${ }^{235} \mathrm{U}$, giving evidence on the right vertical axis of the relative gap between the instantaneous and the realistic depletion calculations. The spectrum variation is underestimated in the OUTLET-punct case.

Inlet and outlet conditions show clearly opposite behavior. A slight power redistribution towards the bottom part of the core is then expected at BOC, while the same may occur in the upper part of the core at the end of the third cycle for a higher content of plutonium with respect to the case using the nominal moderator temperature.

According to the results, instantaneous modification of the coolant density seems acceptable for PWR modelling. These history effects have a stronger impact on the physical representation of the assembly than the varying boron dilution, but the effects caused by long insertion of control rods are more relevant (see 4.4 .
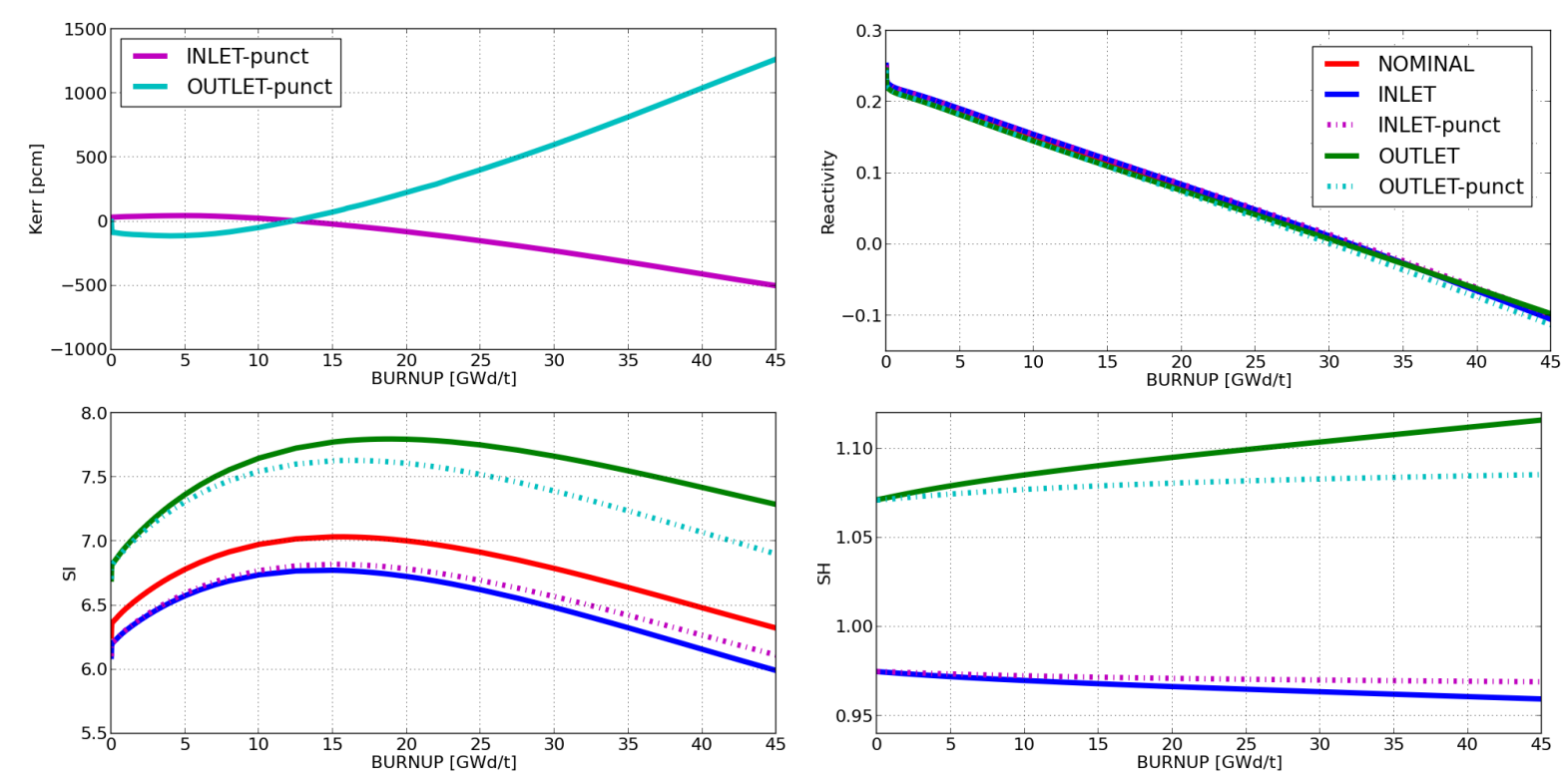

Figure 4: Differences along exposure at nominal HFP conditions with coolant at INLET $\left(287^{\circ} \mathrm{C}\right)$, OUTLET $\left(324^{\circ} \mathrm{C}\right)$ and nominal temperatures $\left(300^{\circ} \mathrm{C}\right.$ pressure of 155 bar $)$. Kerr refers to differences of the multiplication factor between INLET and INLET-punct, OUTLET and OUTLET-punct.

\subsection{Permanent control rod insertion}

Case 5 and 6 from sec. 4.1 are investigated here in more detail, this time with the $B_{1}$ leakage model because it is common in standard practice. The former case represents a controlled permament permanent 


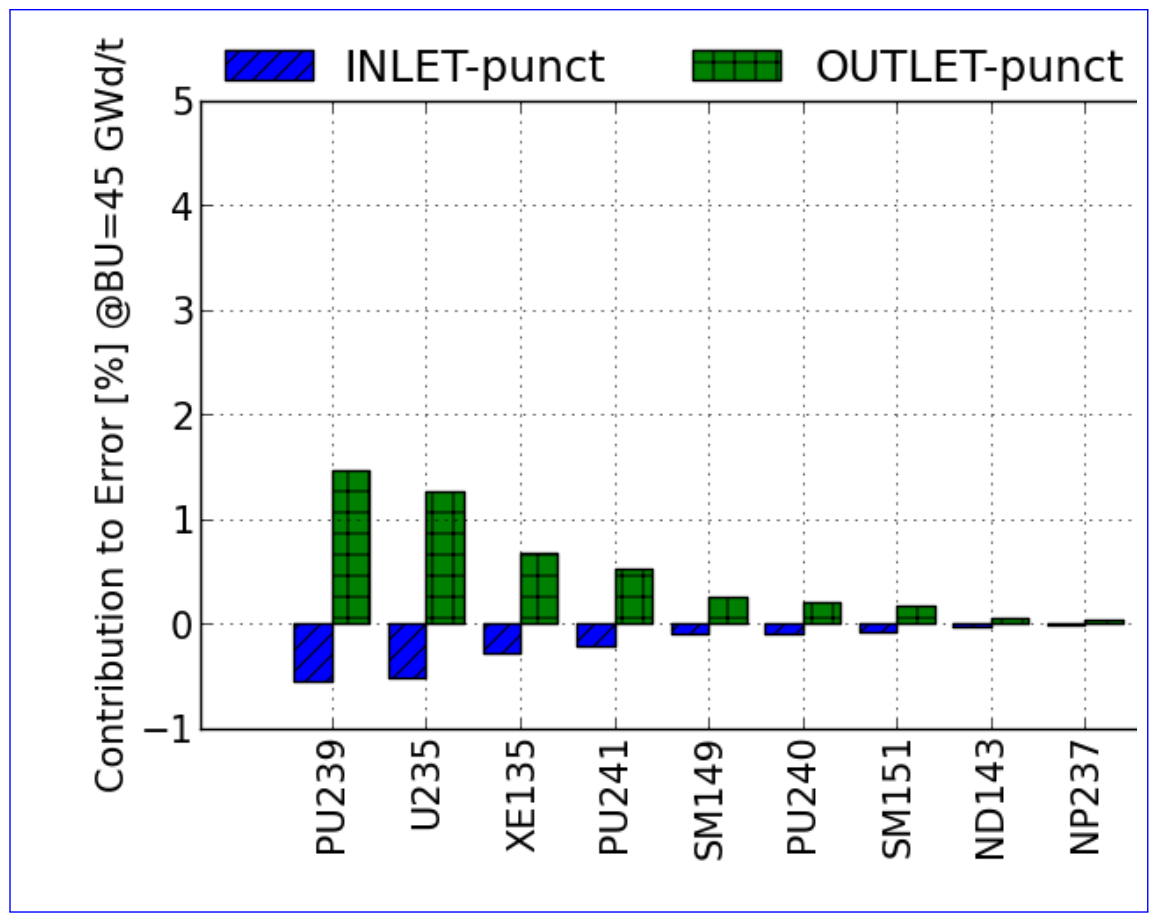

(a)

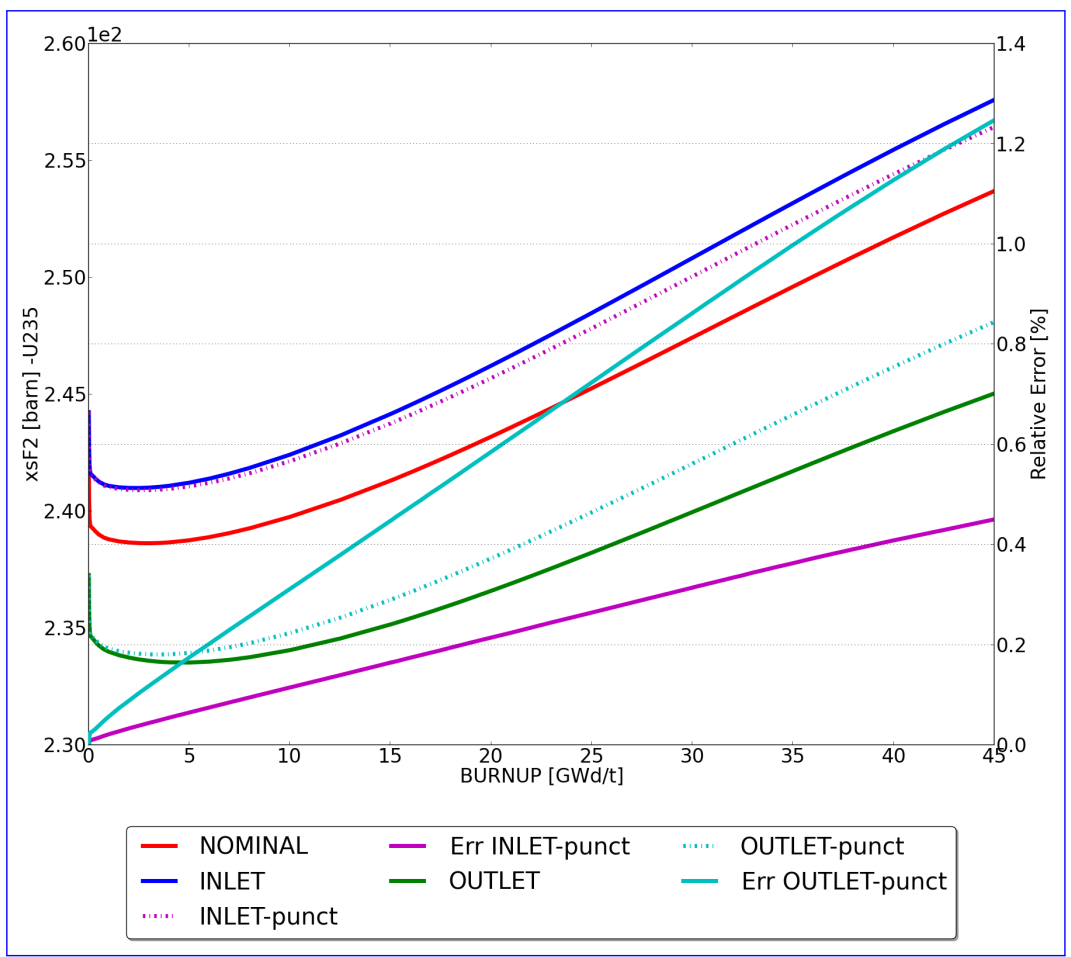

(b)

Figure 5: (a) Contribution of the most important isotopes to the reactivity error in decreasing order. Smaller contributions are not plotted. Importance is evaluated by the sensitivity indices $\partial \rho / \partial N_{i}$ for a variation of $1 \%$ in the concentration of the isotope $N_{i}$. (b) Thermal fission cross section of $235 \mathrm{U}$ in depletions at different moderation. 
situation all along the first cycle, and in the second cycle for the latter. Figs. 6 and 7 show the changes of reactivity, SI and SH. The dotted line represents the results of the calculations from secondary branches that is with rods inserted punctually along the exposure, as in the standard cross section preparation. The distance between this line and the blue one, which reproduces the more physical history of the assembly, is representative of the error on criticality (Kerr in figures). In Case 5, reactivity is reaching a maximum underestimation of $2 \%$, before stabilizing at an offset value of $1.6 \%$. Underestimation of reactivity is higher in Case 6 achieving 3\%. SH increases as expected during the insertion period, but it is still underestimated when the nominal depletion does not account permanent insertion.
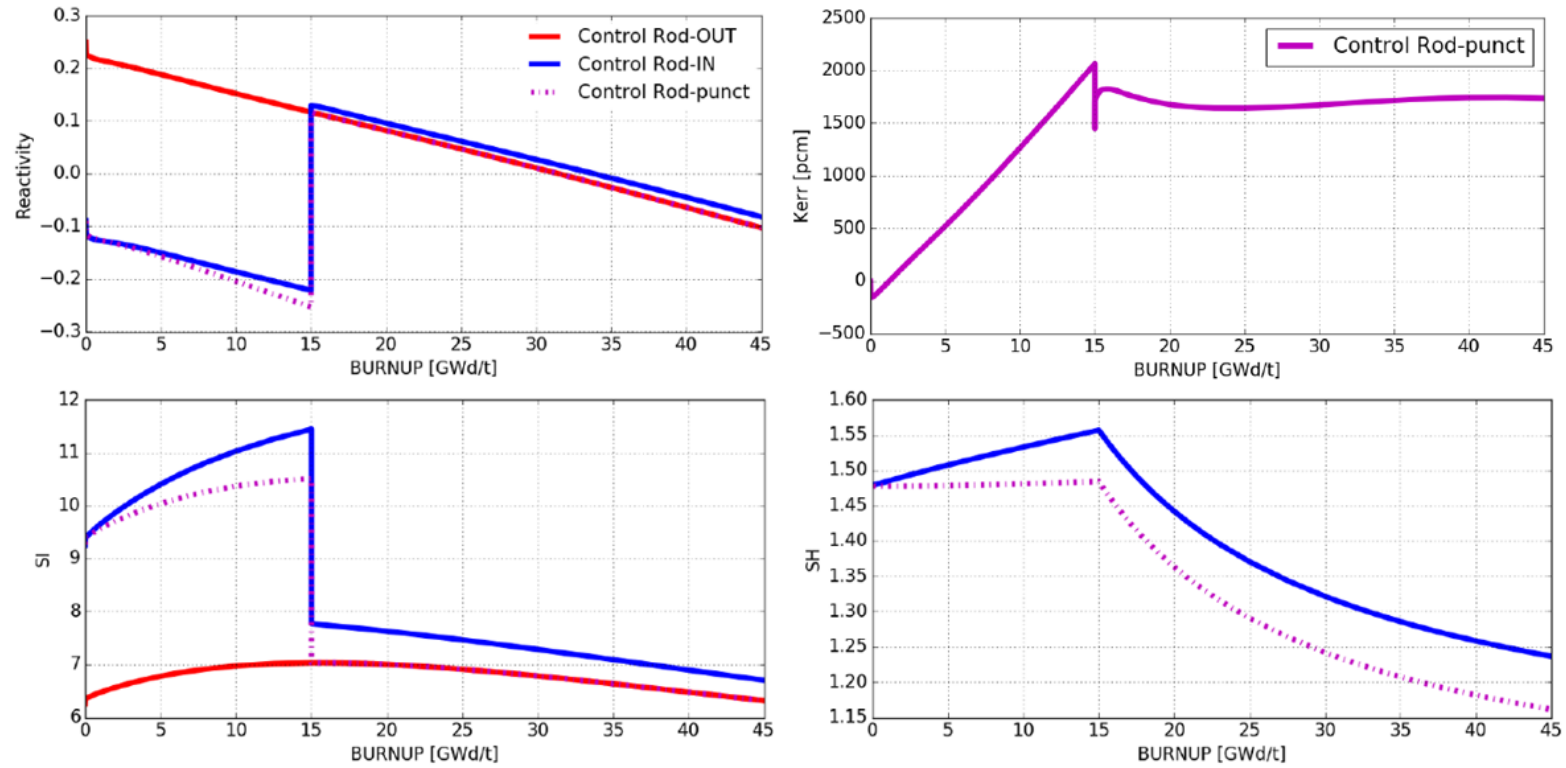

Figure 6: Case 5 - Differences w.r.t. along exposure at nominal HFP conditions.

Concerning the concentrations of ${ }^{239} \mathrm{Pu}$ and ${ }^{235} \mathrm{U}$, differences of about $5 \%$ and $12 \%$ are observed at $45 \mathrm{GWd} / \mathrm{t}$ in Case 5, and $10 \%$ and $11 \%$ in Case 6. Fig. $8 \mathrm{~b}$ shows the isotopes contributing the most to the total error in Case 6, according to the first order sensitivities described in sec. 4.1. The same most contributing isotopes are noticed in Case 5, with the only difference that ${ }^{235} \mathrm{U}$ takes the leading term at EOC, see Fig. 8a. According to figures, the main contributors to the reactivity differences are the same ${ }^{239} \mathrm{Pu}$ and ${ }^{235} \mathrm{U}$ and not ${ }^{238} \mathrm{U}$ that has similar capture rate in both cases. This means that plutonium production is similar in rodded and unrodded configurations, but with much lower consumption in the former case. This saving of fissile material provokes the reactivity gain observed in Figs. 6 and 7 ] (top left plots) when the rods are withdrawn. Finally, one can notice the significant variations in the ${ }^{235} \mathrm{U}$ microscopic cross sections, see for instance Fig. 9 about the thermal fission cross section.

Although these simulations perform very long insertion periods, the absorbing isotopes of the control rods are not considered as depleting. This assumption aims at studying the only influence of the hardened spectrum along exposure. If they are also depleting, the spectrum hardens less but bigger differences in reactivites are expected, as shown in sec. 4.5, with Fig. 10a,

\footnotetext{
${ }^{4} 1 \%$ corresponds to $1000 \mathrm{pcm}$.
} 

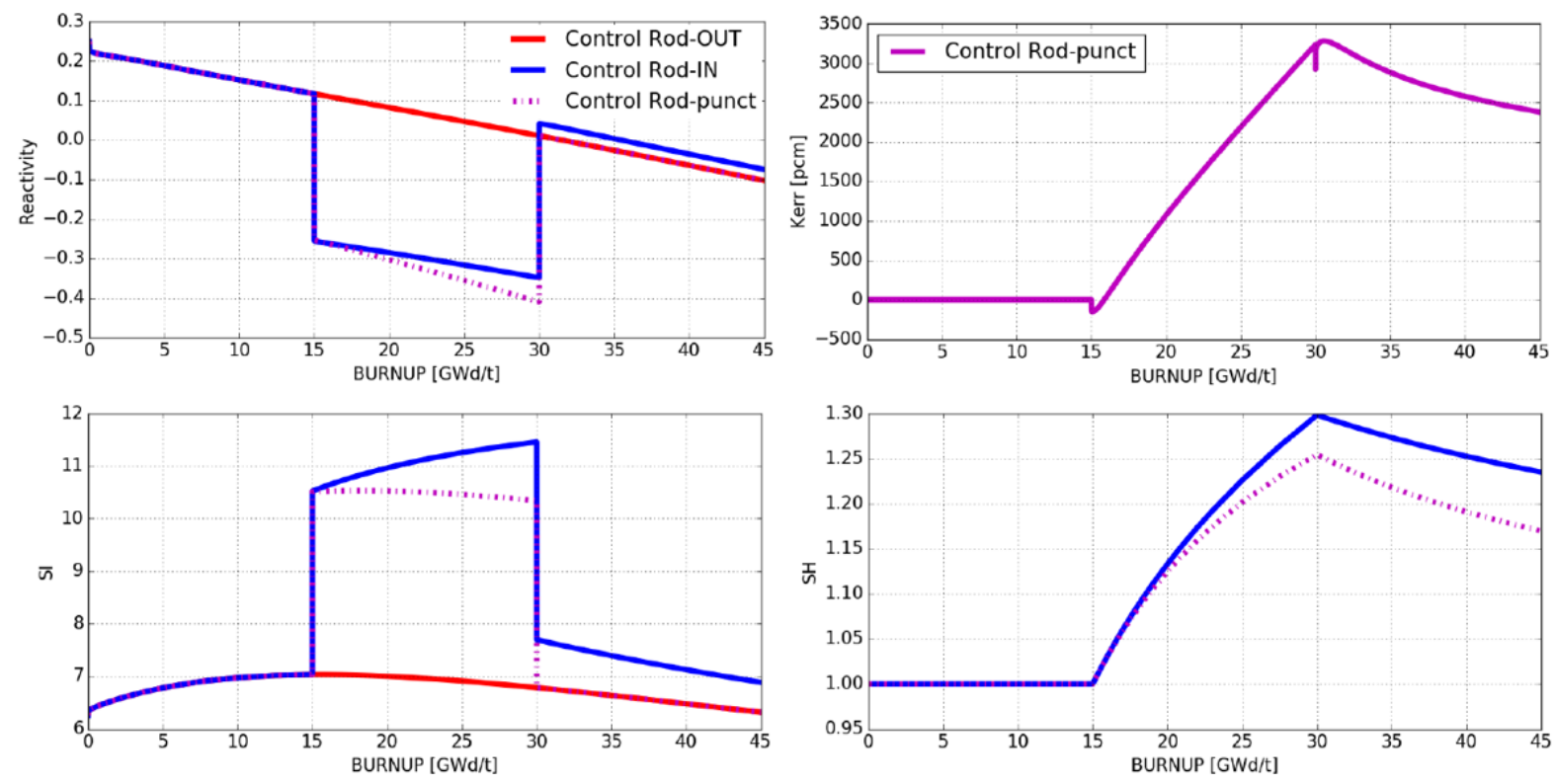

Figure 7: Case 6 - Differences w.r.t. along exposure at nominal HFP conditions.

\subsection{Control rod aging}

In addition to material wearing, consumption can become significant when control rod elements are exposed for long periods to high neutron flux, which is $O\left(10^{13}\right) \mathrm{n} / \mathrm{cm}^{2} / \mathrm{s}$ in thermal reactors. Fig. 10 shows the reactivity evolution of the assembly with and without depletion of the AIC absorbers. When the absorber isotopes are also accounted into the depletion, the rod worth is reduced further mostly due to the consumption of ${ }^{113} \mathrm{Cd}^{5}$, which is almost gone after $15 \mathrm{GWd} / \mathrm{t}$. It follows that the use of black control banks are discouraged with long insertions during the reactor operation. The spectrum hardens less yielding a spectral history increasing slowlier more slowly with the burnup. Although these differences, the amount amounts of plutonium and ${ }^{235} \mathrm{U}$ change slightly, as well as their two group cross sections.

Knowing that the most of the thermal and resonant absorption happens practically on the surface of the fuel close to the moderator, it is interesting to investigate the so-called "skin effect" [19]. The control rod depletes radially inwards, starting from its outer border due to spatial self-shielding. The piecewise piece-wise constant representation of the radial dependency of absorber concentrations and effective cross sections due to the selfshielding self-shielding effect within the absorber pin needs a more detailed mesh refinement than the ordinary fuel pin in order to achieve convergence up to a given tolerance. This applies on both discretizations, for selfshielding self-shielding and depletion calculations. Hereafter, convergence is studied on the absorption cross sections of the control rod pins. The total macroscopic cross section and the microscopic cross section of ${ }^{113} \mathrm{Cd}$ are shown in Fig. 11 with varying number of pin subdivision in concentric rings. Residual error is monotonically decreasing with mesh refinement, yielding less than $0.3 \%$ all along the depletion between the meshes of 16 and 20 rings, the latter being considered as the reference mesh.

The radial profile of the absorber concentration in the pin shows a strong gradient moving inwards with the burnup. If spatial mesh refinement without adaptativity adaptivity along exposure is not available, a fine equivolumic mesh is suggested.

The very strong radial flux gradient makes the mesh with small number of subdivision inadequate,

\footnotetext{
${ }^{5}$ Absorption cross section of thermal neutrons below cadmium cut-off varies between 21000 and 100000 barnsbarn[25].
} 

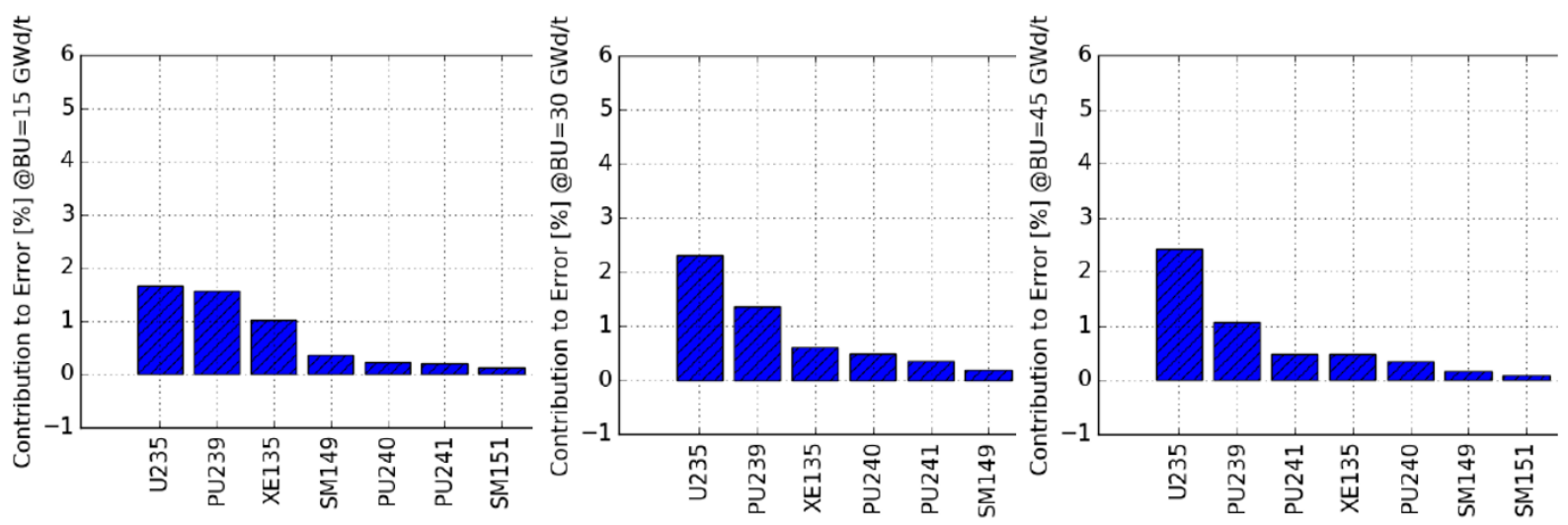

(a) Case 5 .

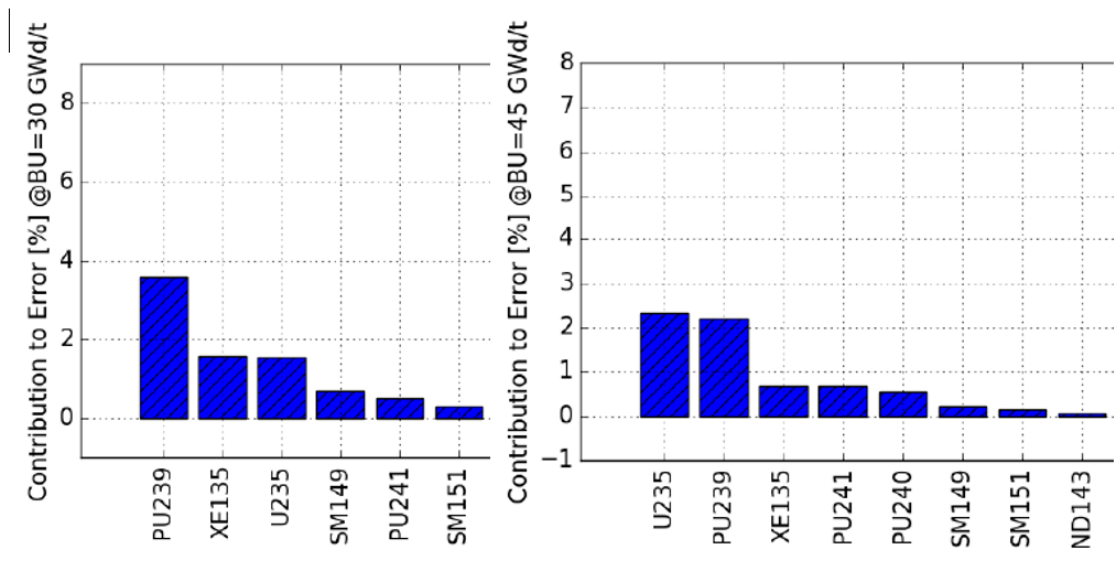

(b) Case 6 .

Figure 8: Contribution of the most important isotopes to the reactivity error, in decreasing order. Smaller contributions are not plotted. Importance is evaluated by the sensitivity indices $\partial \rho / \partial N_{i}$ for a variation of $1 \%$ in the concentration of the isotope $N_{i}$. 


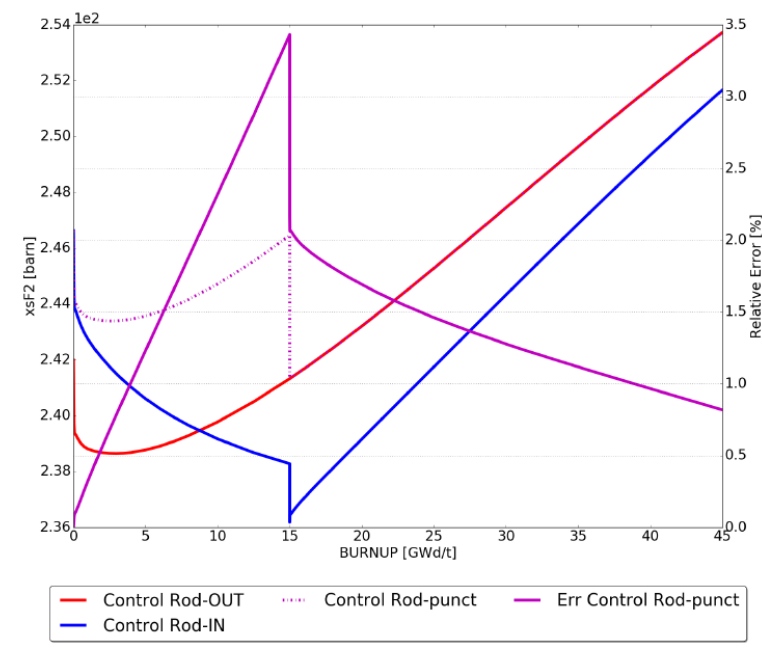

(a) Case 5 .

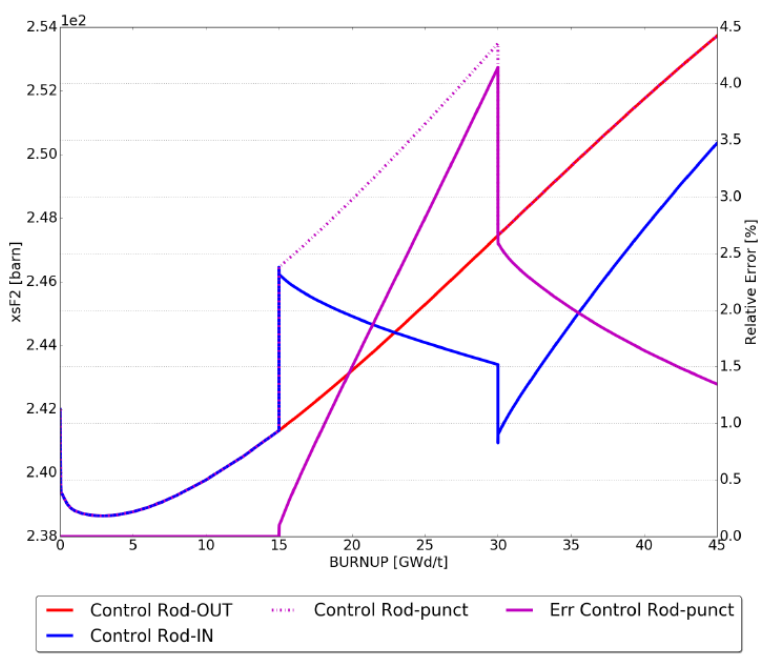

(b) Case 6.

Figure 9: Thermal fission cross sections of ${ }^{235} \mathrm{U}$ with and without permanent rod insertion.

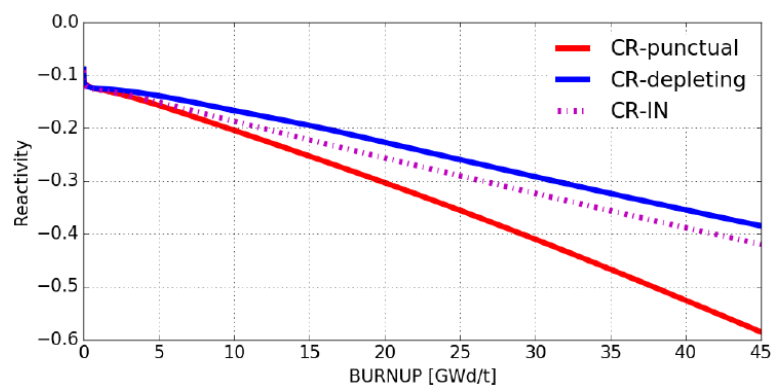

(a) Reactivity.

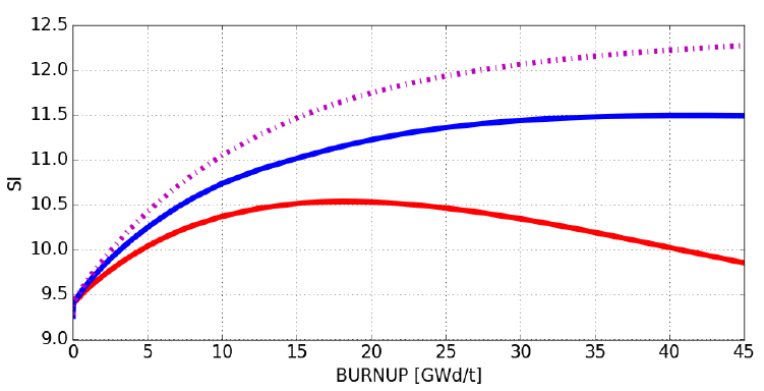

(b) Spectral index.

Figure 10: Reactivity evolution with and without accounting for depletion of AIC absorbers (Case 4). CR-IN: CR inserted along exposure, but with fixed asborber absorber concentrations; CR-depleting: CR inserted along exposure with evolving absorber isotopes; CR inserted only puntually punctually along exposure, fixed absorber concentrations. 


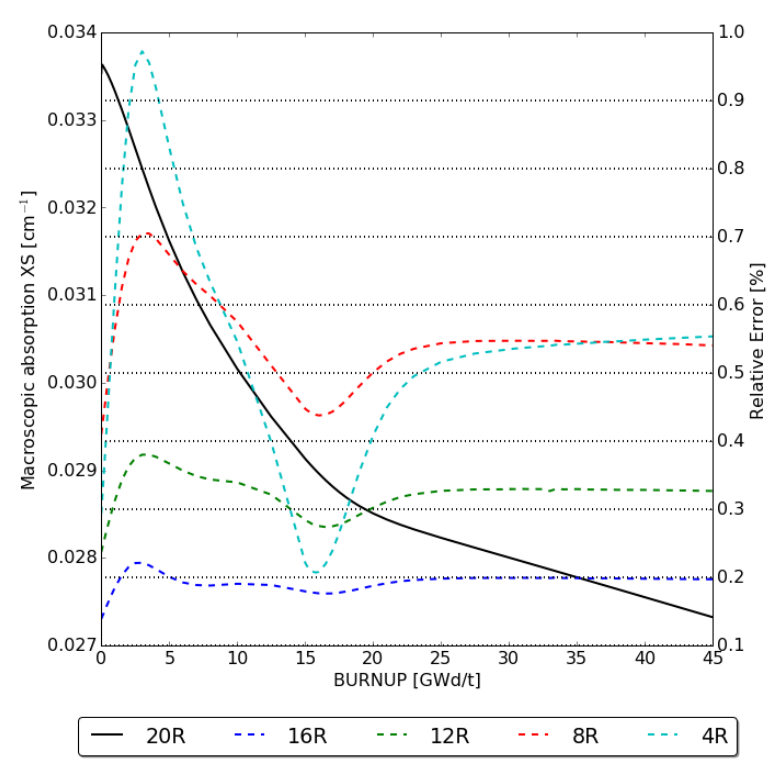

(a) Control rod absorbers

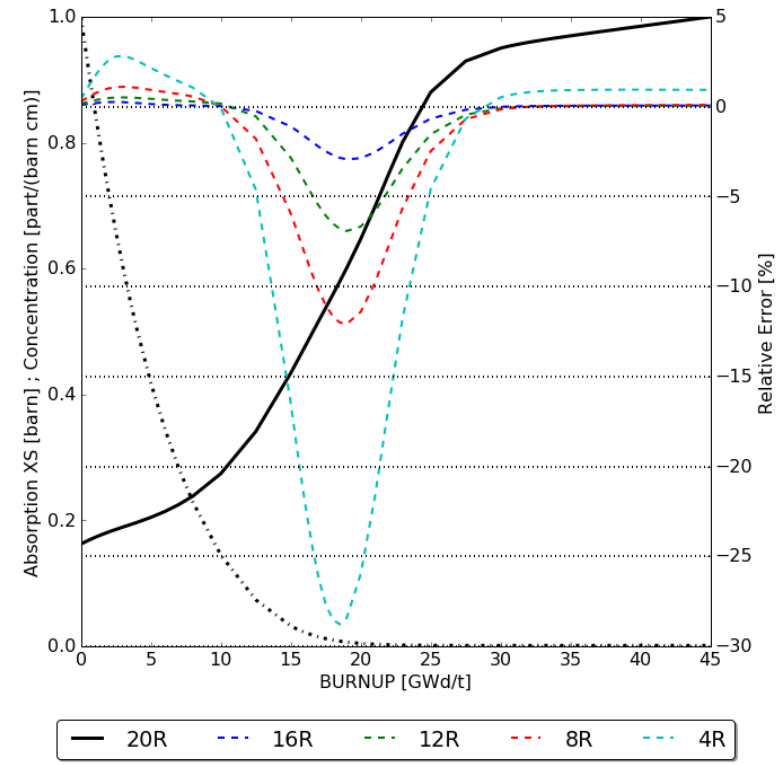

(b) ${ }^{113} \mathrm{Cd}$

Figure 11: (a) Macroscopic cross section (reference with 20 rings - black bold line) and relative error for configurations with 4, 8, 12, and 16 rings (dashed lines). (b) Normalized microscopic cross section (black bold line) and concentration (black bold dash-dotted line), and relative errors in cross section for configurations with 4, 8, 12, and 16 rings (dashed lines). Quantities on the left y-axis are normalized to the corresponding maximum value. 
especially those with 4 and 8 rings. Too wide annular zones with the piecewise piece-wise constant representation results in the overestimation of the cross sections with increased sensibility in the situation where the isotopic concentration actually drops significantly (burnup value around $15 \mathrm{GWd} / \mathrm{t}$ ). The most important contributor to the absorption of this type of control rod is ${ }^{113} \mathrm{Cd}$ (see Fig. 11. b) whose concentration decreases by an order of magnitude. Evidently, the self-shielding effect diminishes as isotope disappears such that the effective microscopic cross section increases.

\subsection{Local pin reaction rates}

Dehomogenization is often needed when using nodal codes to reconstruct local pin reaction rates and evaluate the safety margins. There exist many different techniques for the reconstruction of the pin quantities, but they can hardly take into account many history effects occurring during fuel exposure. They generally show a similar approach by factoring the solution with an intra-nodal polynomial function built with the coarse flux distribution computed online from the core code and the form factors obtained at the initial cross section preparation phase. Tables 5 and 6 shows show the map of power form factors $(\mathrm{PFF})$ of Case 5 at 15 and $30 \mathrm{GWd} / \mathrm{t}$ respectively, that is with permanent rod insertion during the first cycle and recovering the unrodded configuration till the end of the second cycle. PFF are determined by multiplying the two group form factors $(\mathrm{FF})$ for the pin-wise energy production cross sections, which accounts for both released fission energy and neutron radiative capture. As well, FF are simply the fast and thermal pin fluxes in arbitrary units. These distributions are normalized to the total number of pins in the square. Per each pin in the tables, the relative difference of the group PFF with respect to the case without permanent ent-insertion along the nominal depletion (as in the standard preparation) follows the absolute value from Case 5. The first two values refer to the fast group, whereas the others are for the thermal group.

\section{Conclusion}

This work focuses on the standard single assembly procedure for cross sections preparation in PWRs, aiming to investigate the physical accuracy under different profiles of control rod insertions and local conditions. The "Burnup Credit Criticality Benchmark" (OECD benchmark NEA-6227, phase IID) is used to validate the calculation scheme and provide realistic test cases for the study. About the benchmark , good agreement is noticed with APOLLO2.8 2 which is using JEFF3JEFF-3.1.1 libraries and a new solver based on the method of long characteristics, with respect to the results of the other participants. Previous APOLLO results shown in the benchmark report used version 2.5 with JEFF2.1JEFF-2.2.

Because of punctual The boron dilution in the coolant used along the nominal evolution of the assembly has been studied with realistic profiles of the boron concentration. Although punctual differences on all quantities, a constant boron concentration, averaged on the whole fuel cycle to conserve the reactivity, seems reproducing the average behavior of the assembly.

Heated coolant water at core outlet hardens the neutron spectrum, whereas enhanced thermalization is verified at inlet. Possible power misbalance may occur in core calculations with high-burnup fuel when using cross sections prepared with the real local thermal properties.

Because of the instantaneous insertion of control elements along the nominal exposure, a significant underestimation of plutonium production and ${ }^{235} \mathrm{U}$ savings is noticed, increasing in time according to the extended control plan. This outcome was fairly expected, marking a lack in however it demands additional verification in a real core environment in order to evaluate possible improvements in the usual modelling.

The spectral history was computed when analyzing the results. This integral parameter derived from the spectral index is suggested for the functionalization of the homogenized cross sections in order to reproduce the history effects in core calculations.

Also the boron dilution in the coolant used along the nominal evolution of the assembly has been studied with realistic profiles of the boren concentration. Although punctual differences on all quantities, a 
Table 5: Distribution of the power form factors in the lower half of NE quadrant at 15 GWd/t.

\begin{tabular}{|c|c|c|c|c|c|c|c|c|}
\hline $\begin{array}{c}\mathrm{PFF}_{F} \\
\Delta_{F}(\%) \\
\mathrm{PFF}_{T} \\
\Delta_{T}(\%)\end{array}$ & & & & & & & & $\begin{array}{l}1.071 \\
\mathbf{- 9 . 0 4} \\
1.444 \\
\mathbf{- 6 . 2 3}\end{array}$ \\
\hline & & & & & & & 1.075 & 1.070 \\
\hline & & & & & & & -7.29 & -8.31 \\
\hline & & & & & & & 1.343 & 1.398 \\
\hline & & & & & & & -5.13 & -5.77 \\
\hline & & & & & & 1.066 & 1.069 & 1.070 \\
\hline & & & & & & -2.50 & -5.58 & -7.08 \\
\hline & & & & & & 1.184 & 1.285 & 1.352 \\
\hline & & & & & & -1.30 & -3.92 & -5.04 \\
\hline & & & & & 0.687 & 1.060 & 1.064 & 1.067 \\
\hline & & & & & -5.20 & +1.63 & -3.41 & -5.56 \\
\hline & & & & & 0.221 & 1.060 & 1.217 & 1.305 \\
\hline & & & & & -9.50 & +2.59 & -2.28 & -4.05 \\
\hline & & & & 1.042 & 1.045 & 1.052 & 1.059 & 1.058 \\
\hline & & & & +4.83 & +5.77 & +3.83 & -1.23 & -4.14 \\
\hline & & & & 0.927 & 0.905 & 0.981 & 1.147 & 1.260 \\
\hline & & & & +3.92 & +5.52 & +4.21 & -0.62 & -3.15 \\
\hline & & & 0.675 & 1.040 & 1.046 & 0.689 & 1.054 & 1.058 \\
\hline & & & -4.81 & +5.51 & +5.39 & -5.10 & +1.20 & -2.98 \\
\hline & & & 0.210 & 0.915 & 0.920 & 0.225 & 1.079 & 1.227 \\
\hline & & & -9.94 & +4.91 & +5.10 & -9.49 & +1.82 & -2.26 \\
\hline & & 1.034 & 1.035 & 1.038 & 1.043 & 1.047 & 1.049 & 1.053 \\
\hline & & +2.46 & +4.77 & +3.16 & +2.86 & +3.59 & -0.21 & -2.83 \\
\hline & & 1.026 & 0.950 & 0.986 & 0.995 & 0.988 & 1.111 & 1.220 \\
\hline & & +1.59 & +4.20 & +2.13 & +2.01 & +3.52 & -0.18 & -2.43 \\
\hline & 1.031 & 1.032 & 1.035 & 1.038 & 1.041 & 1.045 & 1.048 & 1.050 \\
\hline & -0.16 & +1.76 & +4.50 & +2.94 & +2.65 & +3.53 & -0.09 & -2.65 \\
\hline & 1.167 & 1.063 & 0.963 & 0.995 & 1.002 & 0.988 & 1.108 & 1.213 \\
\hline & -0.50 & +1.08 & +3.98 & +1.92 & +1.75 & +3.40 & -0.15 & -2.35 \\
\hline 0.002 & 1.027 & 1.030 & 0.678 & 1.037 & 1.041 & 0.687 & 1.050 & 1.053 \\
\hline-4.72 & -0.51 & +3.11 & -4.73 & +4.75 & +4.51 & -4.97 & +1.59 & -2.33 \\
\hline 0.004 & 1.232 & 1.038 & 0.221 & 0.943 & 0.950 & 0.226 & 1.064 & 1.205 \\
\hline-7.56 & -0.40 & +2.86 & -9.54 & +4.15 & +4.04 & -9.45 & +1.88 & -1.97 \\
\hline
\end{tabular}


Table 6: Distribution of the power form factors in the lower half of the NE quadrant at 30 GWd/t.

\begin{tabular}{|c|c|c|c|c|c|c|c|c|}
\hline $\begin{array}{c}\mathrm{PFF}_{F} \\
\Delta_{F}(\%) \\
\mathrm{PFF}_{T} \\
\Delta_{T}(\%)\end{array}$ & & & & & & & & $\begin{array}{l}1.072 \\
-\mathbf{- 7 . 6 9} \\
1.019 \\
\mathbf{- 4 . 9 6}\end{array}$ \\
\hline & & & & & & & 1.094 & 1.079 \\
\hline & & & & & & & -6.26 & -7.08 \\
\hline & & & & & & & 1.008 & 1.012 \\
\hline & & & & & & & -4.24 & -4.65 \\
\hline & & & & & & 1.114 & 1.099 & 1.089 \\
\hline & & & & & & -2.40 & -4.85 & -6.07 \\
\hline & & & & & & 1.074 & 1.028 & 1.020 \\
\hline & & & & & & -1.57 & -3.43 & -4.19 \\
\hline & & & & & 0.002 & 1.130 & 1.107 & 1.097 \\
\hline & & & & & -5.50 & +0.79 & -3.10 & -4.82 \\
\hline & & & & & 0.004 & 1.155 & 1.056 & 1.036 \\
\hline & & & & & -7.65 & +1.28 & -2.32 & -3.56 \\
\hline & & & & 1.150 & 1.150 & 1.140 & 1.120 & 1.100 \\
\hline & & & & +3.54 & +4.12 & +2.54 & -1.35 & -3.65 \\
\hline & & & & 1.191 & 1.225 & 1.195 & 1.094 & 1.055 \\
\hline & & & & +2.55 & +3.75 & +2.65 & -1.02 & -2.92 \\
\hline & & & 0.002 & 1.151 & 1.149 & 0.002 & 1.129 & 1.107 \\
\hline & & & -5.26 & +4.04 & +3.88 & -5.45 & +0.47 & -2.72 \\
\hline & & & 0.004 & 1.208 & 1.207 & 0.004 & 1.145 & 1.069 \\
\hline & & & -8.63 & +3.11 & +3.23 & -7.77 & +0.75 & -2.36 \\
\hline & & 1.136 & 1.146 & 1.142 & 1.142 & 1.141 & 1.123 & 1.109 \\
\hline & & +1.71 & +3.44 & +2.30 & +2.02 & +2.42 & -0.50 & -2.58 \\
\hline & & 1.142 & 1.193 & 1.148 & 1.144 & 1.176 & 1.103 & 1.069 \\
\hline & & +0.50 & +2.46 & +0.99 & +0.92 & +2.04 & -0.69 & -2.44 \\
\hline & 1.113 & 1.129 & 1.144 & 1.143 & 1.141 & 1.141 & 1.125 & 1.110 \\
\hline & -0.39 & +1.12 & +3.20 & +2.11 & +1.85 & +2.37 & -0.40 & -2.42 \\
\hline & 1.122 & 1.136 & 1.189 & 1.144 & 1.138 & 1.173 & 1.104 & 1.070 \\
\hline & -1.27 & +0.06 & +2.29 & +0.83 & +0.74 & +1.94 & -0.68 & -2.41 \\
\hline 0.002 & 1.096 & 1.130 & 0.002 & 1.148 & 1.147 & 0.002 & 1.134 & 1.112 \\
\hline-5.20 & -0.73 & +2.06 & -5.21 & +3.40 & +3.19 & -5.37 & +0.81 & -2.20 \\
\hline 0.004 & 1.142 & 1.178 & 0.004 & 1.189 & 1.185 & 0.004 & 1.146 & 1.074 \\
\hline-7.39 & -1.32 & +1.39 & -8.31 & +2.48 & +2.41 & -7.90 & +0.78 & -2.20 \\
\hline
\end{tabular}


constant boron concentration, averaged on the whole fuel cycle to conserve the reactivity, seems reproducing the average behavior of the assemblyOther global parameter integrated along exposure are also noticed in literature. We remark, for instance, the moderator density history parameter suggested by Mosteller [15].

Extreme situations are represented with black control rods, see for instance the benchmark case number four 4 , in order to get more insight on the neutron physics. Because of the absorber consumption, lighter control banks are suggested for long term insertion at operation, as noticed in the latest design of PWRs and in recent small modular reactors. Due to the "skin effect", meshes with 11 annuli in the control rod geometry are recommended to provide accurate results by APOLLO2.8.

Differences of second order are noticed on the cross sections homogenized in the assembly quarters, whereas differences of several percent are computed on the local pin factors. This proves the need of specific corrections in dehomogenization methods in order to predict accurately local powers.

The use of reflected boundary conditions in the modeling can be questioned since neighboring assemblies are normally unrodded. Also, Though questionable, a leakage model was employed to follow the standard procedure of cross section preparation. Depletion scenarios with the same given HFP level in the rodded assembly without the leakage model shows a higher increasing spectral index, meaning higher fissile savings too.

Eventually, depletion at full nominal power in rodded assemblies should be relaxed to lower values since power modulation is the goal of control rod insertion. This is supposed overestimating the production of plutonium, serving here the purpose of underlining the main trends and error in the physical modelling.

Such a power level should be estimated from 3D core calculations. Simulations in more realistic environments with neighboring fuel assemblies will be the subject of future studies. 


\section{References}

[1] RD Lawrence. Progress in nodal methods for the solution of the neutron diffusion and transport equations. Progress in Nuclear Energy, 17(3):271-301, 1986.

[2] Kord S Smith. Assembly homogenization techniques for light water reactor analysis. Progress in Nuclear Energy, 17(3):303-335, 1986.

[3] Alain Hebert. A consistent technique for the pin-by-pin homogenization of a pressurized water reactor assembly. Nuclear Science and Engineering, 113(3):227-238, 1993.

[4] Richard Sanchez. Assembly homogenization techniques for core calculations. Progress in Nuclear Energy, 51(1):14-31, 2009.

[5] Jan Dufek. Building the nodal nuclear data dependences in a many-dimensional state-variable space. Annals of Nuclear Energy, 38(7):1569-1577, 2011.

[6] Masaaki Onoue, Tomohiro Kawanishi, William R Carlson, and Toshio Morita. Application of MSHIM core control strategy for Westinghouse AP1000 nuclear power plant. GENES4/ANP2003, pages 15-18, 2003.

[7] Alain Grossetete. Le pilotage de l'EPR: mode T. Revue générale nucléaire, (3):37-41, 2007. (in French).

[8] CH Lee, YJ Kim, JW Song, and CO Park. Incorporation of a new spectral history correction method into local power reconstruction for nodal methods. Nuclear science and engineering, 124(1):160-166, 1996.

[9] Tatsuya Iwamoto and Munenari Yamamoto. Advanced nodal methods of the few-group BWR core simulator NEREUS. Journal of nuclear science and technology, 36(11):996-1008, 1999.

[10] DM Baturin and SB Vygovskii. Taking account of the spectral history of fuel burnup during the preparation of the neutron-physical constants for VVER-1000 fuel assemblies. Atomic Energy, 90(4):267$272,2001$.

[11] José M Aragonés. Fundamentals of 3-D Neutron Kinetics and Current Status. THICKET-2008, CSNI-NEA-OCDE Seminar, Pisa (Italy), may 2008.

[12] I Bilodid and S Mittag. Use of the local $\mathrm{Pu}-239$ concentration as an indicator of burnup spectral history in DYN3D. Annals of Nuclear Energy, 37(9):1208-1213, 2010.

[13] Erwin Müller, Larry Mayhue, and Baocheng Zhang. Reactor physics methods development at Westinghouse. In Proc. Int. Conf. Nuclear Energy for New Europe 2007, 2007.

[14] P Guimarães and Erwin Müller. Parameterization of two-group nodal cross section data for POLCA-T BWR transient applications. In International Conference on Mathematics, Computational Methods, E Reactor Physics, 2009.

[15] RD Mosteller. Impact of moderator history on physics parameters in pressurized water reactors. Nuclear Science and Engineering, 98(2):149-153, 1988.

[16] Anne Barreau. Burn-up Credit Criticality Benchmark. Technical Report Phase, IID and Assembly, PWRUO, OECD-NEA, 2006. PWR-UO2 Assembly Study of Control Rod Effects on Spent Fuel Composition.

[17] R. Sanchez at al. APOLLO2 Year 2010. Nucl. Eng. and Technology, 42:474-499, 2010.

[18] Fausto Franceschini, Baocheng Zhang, Larry Mayhue, Erwin Müller, and Petri Forslund Guimarães. Development of a control rod depletion methodology for the Westinghouse NEXUS system. Progress in Nuclear Energy, 68:235-242, 2013. 
[19] P. Eric Collins, Nicholas Luciano, and G. Ivan Maldonado. Parametric study to capture the skin effect in PWR control rod depletion. Transaction of the American Nuclear Society, 109:1327-1329, 2013.

[20] Venard et al. Contribution of the Experimental Validation of the French Criticality-Safety Package CRISTAL V1: APOLLO2 SN Route. In ICNC2003, Tokai, Japan, 20-24 October 2003, 2003.

[21] M. Coste-Delclaux. Modélisation du phénomene d'autoprotection dans le code de transport multigroupe APOLLO2. CEA-R-6114, 2006. (in French).

[22] Alain Hébert. Applied reactor physics. Presses inter Polytechnique, 2009.

[23] Taylor P. D. P. Rosman, K. J. R. Isotopic composition of the elements 1997. Pure and Applied Chemistry, 70(1):217-235, 1998.

[24] Pierre Coppolani. La chaudière des réacteurs à eau sous pression. EDP Sciences, 2012. (in French).

[25] TJ Pashos. Materials for Control of Water Cooled Power Reactors. Nuclear Technology, 4(6):395-398, 1968. 